\title{
Um tributo à professora Maria Laura (1919 - 2013)
}

\section{Claudia Segadas}

Professora associada do IM - UFRJ

Projeto Fundão e PEMAT - IM-UFRJ

claudia@im.ufrj.br

\section{Lilian Nasser}

Professora adjunta do IM - UFRJ

Projeto Fundão e PEMAT - IM-UFRJ

lnasser@im.ufrj.br

\author{
Lucia A. de A. Tinoco \\ Professora adjunta do IM - UFRJ \\ Projeto Fundão - IM - UFRJ \\ luciaatinoco@gmail.com \\ Telefone e FAX: 21-2562-7511
}

\section{Resumo}

Este artigo é uma homenagem à professora Maria Laura Mouzinho Leite Lopes, fundadora do GEPEM e do Projeto Fundão, que faleceu recentemente, em junho de 2013. Em meio às diversas homenagens e destaques dados à sua história de vida, nós, que tivemos o privilégio da sua convivência ao longo dos 30 anos do Projeto Fundão, optamos por destacar suas características mais marcantes, que faziam de Maria Laura uma educadora, pesquisadora e, principalmente, amiga incomparável. Seu entusiasmo e otimismo contagiantes promoveram a permanência e continuidade de um dos projetos mais duradouros da história das Universidades brasileiras, integrando diferentes unidades e centros da UFRJ, com o objetivo de apoiar os professores da Escola Básica e, consequentemente, melhorar a aprendizagem significativa dos alunos.

Palavras-chave: História; Educação Matemática; Projeto Fundão; Homenagem.

\section{A tribute to professor Maria Laura (1919 - 2013)}

\begin{abstract}
This text is in honor to Professor Maria Laura Mouzinho Leite Lopes, founder of GEPEM and Projeto Fundão, who died recently, in June, 2013. Along with the many homages and highlights given for her story of life, we, who had the privilege of being and working with her during the 30 years of the Projeto Fundão, chose to highlight her most striking features, which made Maria Laura an educator, researcher and, mainly, an incomparable friend. Her contagious enthusiasm and optimism ensured the permanence and continuity of one of the most enduring projects in the history of Brazilian Universities, integrating different units and centers of UFRJ, aiming to support teachers of primary and secondary level and, hence, improve students' meaningful learning.
\end{abstract}

Keywords: History; Mathematics Education; Fundão Project; homage. 
Como caracterizar a Maria Laura? São tantas as marcas importantes dessa grande personalidade! Ressaltaremos umas poucas observadas nesses 33 anos de convivência.

\section{Fortaleza e delicadeza}

Todas as características apresentadas sobre a personalidade da Maria Laura revelam uma personalidade forte, determinada e líder inata. Estes atributos vinham conjugados à doçura, preocupação com os outros e muita bondade. Gostava de crianças e aconselhava os pais, seus amigos. Era também solidária nos momentos de doença ou tristeza. Boa ouvinte, no meio de uma ou outra conversa nos telefonemas que dava, inseria algum conselho, valioso de quem tinha grande experiência de vida, mas sem deixar a impressão de quem acha que sabe mais. Lia muito e adorava comentar sobre os livros, adorava biografias e queria continuar aprendendo, se inspirando com grandes líderes ou personalidades. Gostava que lêssemos também para trocar ideias e comentários. Assim, poderíamos compartilhar não somente conhecimentos acadêmicos, mas de cultura, de vida.

\section{Liderança}

Maria Laura fez parte da geração que consolidou as ciências no Brasil: participou da fundação do Conselho Nacional de Pesquisas (atual Conselho Nacional de Desenvolvimento Científico e Tecnológico - CNPq), do Centro Brasileiro de Pesquisas Físicas (CBPF) e do Instituto de Matemática Pura e Aplicada (IMPA). Foi a primeira mulher brasileira a ser admitida como membro associado da Academia Brasileira de Ciências e a primeira doutora em Matemática do Brasil.

Como professora da Faculdade Nacional de Filosofia (FNFi) da Universidade do Brasil (atual Universidade Federal do Rio de Janeiro - UFRJ), assumiu a cátedra interina de Geometria em 1953 e, como tal, passou a membro da Congregação dessa Faculdade, com atuação destacada, sempre ao lado dos que lutavam por mudanças na Universidade e no Brasil. Com esse espírito, após breve afastamento do país, passou a integrar em 1967, como Professor Titular, o corpo docente do recém criado Instituto de Matemática da Universidade Federal do Rio de Janeiro, que absorveu o Departamento de Matemática da FNFi, do qual era a chefe na ocasião. Nesta condição de líder crítica à reforma realizada na Universidade e à política vigente no Brasil, atuou até ser compulsoriamente afastada pelo governo da ditadura militar, em 1969.

Essas características, juntamente com a fortaleza de sua personalidade, explicam a amplidão da atuação da Maria Laura na UFRJ, após sua reintegração, em 1980. Como é notório na comunidade acadêmica, sua meta principal na ocasião era 
implantar a Educação Matemática, como área de pesquisa, nessa universidade e fora dela. Observa-se que o seu amor à Universidade se manifestava também em muitos outros sentidos, sempre aliado à sua capacidade de liderança.

Foi Diretora Adjunta de Graduação do Instituto de Matemática, onde inovou criando o prêmio Amoroso Costa para alunos de graduação. Maria Laura foi escolhida por seus pares como representante dos professores titulares no Conselho do Centro de Ciências Matemáticas e da Natureza (CCMN) e no Conselho Universitário da UFRJ. No sentido de contribuir para o debate de ideias a respeito da concepção de universidade, aceitou disputar eleições para a Decania do CCMN e para a Reitoria da UFRJ.

A dedicação e competência dedicadas por Maria Laura à Universidade Federal do Rio de Janeiro e à comunidade científica brasileira a levaram a receber o título de professora Emérita da UFRJ, em 1996, e a Comenda da Ordem Nacional do Mérito Científico, do Ministério da Ciência e Tecnologia do Brasil, em 2010.

Todos esses títulos e lutas de Maria Laura a caracterizaram como uma líder nata, mas foi nos últimos trinta e nove anos, após o seu reingresso ao Brasil em 1974, que a comunidade de educadores matemáticos passou a conhecer tal liderança.

Embora ainda impedida de atuar na UFRJ, estava disposta a colocar sua energia em favor da Educação Matemática brasileira. Neste sentido, ao reencontrar amigos educadores do Rio de Janeiro, como Ana Averbuch (1928 - 2004), passou a atuar como orientadora do pré-escolar na Escola Israelita Brasileira Eliezer Steinbarg e no Centro Educacional de Niterói.

Como relata Pereira (2010), neste período, Maria Laura junta-se aos professores José Carlos Melo e Souza (1905-1990), Moema Sá Carvalho e Ana Averbuch para criar em 1976 o GEPEM - Grupo de Ensino e Pesquisa em Educação Matemática, que presidiu durante oito anos, ainda hoje em evidência com este reconhecido BOLETIM. Como presidente do GEPEM coordenou o "Seminário, Sobre Ensino da Matemática" realizado na Academia de Ciências, no Rio de Janeiro em 1976.

Também como presidente do GEPEM, Maria Laura coordenou a pesquisa experimental "Projeto Binômio Professor-Aluno na Iniciação à Educação Matemática", resultante de convênio com o MEC/INEP (contrato 06/79), considerada a primeira pesquisa nesta área no Brasil, publicada pelo Boletim do GEPEM, com apoio da Fundação Universitária José Bonifácio da UFRJ.

A essa época, já existia no Instituto de Matemática (IM/UFRJ) uma tentativa de um grupo de professores de realizar trabalho relacionado a Educação Matemática, com forte reação do corpo docente do Instituto. Foi então que entrou em jogo a capacidade de liderança da Professora Maria Laura: assim que reassumiu suas funções na UFRJ, aliou-se a esse grupo, agregando a ele outros elementos e fortalecendo-o para elaborar e implementar o primeiro programa oficial de Educação Matemática 
do IM/UFRJ: o Programa de Formação Permanente de Professores de $1^{\circ}, 2^{\circ}$ e $3^{\circ}$ Graus - com o apoio da SESU/MEC, como parte do Programa de Integração da Universidade com o Ensino de $1^{\circ}$ Grau. Esse foi o embrião do Projeto Fundão.

Maria Laura teve participação decisiva na fundação da Sociedade Brasileira de Educação Matemática (SBEM), tendo presidido, em 1988, a assembleia de sua criação, durante o II Encontro Nacional de Educação Matemática (II ENEM), realizado em Maringá, PR. Juntamente com o Professor Ubiratan D’Ambrosio, recebeu o título de Presidente de Honra dessa sociedade. Na comemoração dos 25 anos da SBEM, durante o XI Encontro Nacional de Educação Matemática em julho de 2013, Maria Laura recebeu homenagem especial, em reconhecimento à sua importância na consolidação da área de Educação Matemática no Brasil.

\section{Inovação e Ousadia}

Mencionamos anteriormente algumas ações da Maria Laura enquanto membro da comunidade acadêmica do Brasil, reconhecendo em todas elas um caráter inovador. Na verdade, ela lutou desde muito cedo por transformar a sociedade científica do país, com vistas a uma transformação sócio-educacional do próprio país. Coerentemente, em seu discurso, ao receber o título de Professora Emérita da UFRJ, citou Laurent Schwartz (1983): "Il n'y a pás d'exemple de pays développé ayant une université sousdéveloppé” (Não há exemplo de país desenvolvido tendo uma universidade subdesenvolvida - tradução nossa) (apud LEAL e LOPES, 2013).

Na Faculdade Nacional de Filosofia (FNFi) da Universidade do Brasil, onde lecionou desde 1940, sendo ainda aluna, e após sua formatura em 1942, Maria Laura tinha um papel inovador. Suas aulas se distinguiam pela procura de formas não usuais de incentivar a aprendizagem, como, por exemplo, já naquela época, trazer uma faixa de papel para mostrar a "faixa de Möebius" em uma aula de graduação, ao mesmo tempo em que apresentava com naturalidade noções abstratas com a de "plano projetivo".

Em texto recente enviado à sua família por ocasião da morte de Maria Laura, seu ex-aluno em 1946 e ilustre matemático brasileiro, Paulo Ribenboim escreve:

[...] encontrei uma professora linda. Falava com conhecimento do que queria explicar. Imediatamente soube que seria a minha professora. $\mathrm{O}$ curso era de geometria analítica e projetiva; o livro, em espanhol, de Guido Castelnuovo. Não sabia então, mas vim a saber muito posteriormente que Castelnuovo era um dos grandes geômetras da época. Maria Laura, que compreendeu muito bem o assunto, soube transmiti-lo com grande rigor e minúcia, sem enfado. Não (grifo 
nosso) como outros professores, imaginem, de costas para os alunos, com giz escrevendo palavra por palavra, copiadas de notas, que maneira de transmitir!

O primeiro ano com Maria Laura foi para mim muito proveitoso. Já naquela época longínqua Maria Laura demonstrava qualidades didáticas fora do comum, uma antecipação do que viria a ser.

A atuação da Maria Laura na Congregação da FNFi, onde trabalhou sempre no sentido de apoiar ideias avançadas para o seu tempo, pode ter contribuído para a sua aposentadoria compulsória ao ser promulgado o Ato Institucional $\mathrm{n}^{\circ} 5$.

Não foi diferente sua atitude ao regresssar do exílio trazendo em sua bagagem a convicção de que a Educação Matemática era uma área de pesquisa importante e essencial para a melhoria da qualidade do ensino de matemática em qualquer lugar. Citava frequentemente seu amigo, o pesquisador Georges Glaeser, ao defender que as dificuldades, estratégias e métodos inerentes aos processos de ensino e de aprendizagem em Matemática deveriam ser objetos de pesquisa.

Foi com essa postura que, enquanto presidente do GEPEM, rompeu a impossibilidade de este grupo se responsabilizar oficialmente por um curso de pós-graduação e, em acordo com a Universidade Santa Úrsula (USU), liderou a equipe daquele Grupo na fundação em 1980 do primeiro curso de Especialização em Educação Matemática em nosso país, em nível de pós-graduação lato sensu. Este curso torna-se o embrião do segundo Curso de Mestrado em Educação Matemática no Brasil, também oferecido pela USU, sob a coordenação da Professora Estela Kauffman Fainguelernt.

Neste ano de 1980 a Professora Maria Laura é reintegrada à Universidade Federal do Rio de Janeiro, onde passou a lutar pelos mesmos ideais de consolidar a área de pesquisa em Educação Matemática, numa época (1980) em que tais assuntos eram tidos como totalmente inadequados para o ambiente acadêmico de um Instituto de Matemática da maior universidade federal do Brasil.

Com a ousadia que lhe era peculiar, Maria Laura encorajava alunos e participantes do Projeto Fundão a avançar nos estudos de Educação Matemática, cursando pós-graduação na área. Foi devido ao seu incentivo que vários professores brasileiros conseguiram apoio da CAPES para cursar doutorado no exterior, além de um grande número de mestrados no Brasil.

O espírito de luta e o legado deixado por ela pode ser ilustrado pela última frase da moção de pesar que o Conselho Universitário da UFRJ divulgou por ocasião de sua morte:

"Ficam seus ensinamentos, suas conviç̧oes, seu exemplo de vida e de luta. A UFRJ fica menor ao perder essa grande brasileira." (apud LEAL e LOPES, 2013). 


\section{Visão ampla das Ciências}

$\mathrm{Na}$ Congregação da Faculdade Nacional de Filosofia havia um clima universitário de fato, com debate frequente de ideias e visões sobre todas as ciências exatas, sociais e humanas, permitindo a construção de uma concepção ampla de ciência, impregnada de história e cultura. Isto porque na FNFi funcionavam cursos de ciências, letras, filosofia, história, pedagogia e outros, ao todo, dezoito cursos em um só prédio, com uma mesma Congregação.

Além da experiência na FNFi, Maria Laura, nos anos 40, 50 e início dos 60, viveu intensamente o processo de consolidação das ciências no Brasil, por meio do qual, com extrema capacidade de fazer relações, tornou-se amiga de pensadores, cientistas e artistas de renome como Cesar Lattes, Carlos Chagas, Celso Furtado, Darcy Ribeiro, Alceu Amoroso Lima, Fayga Ostrower, Haity Moussatché, os irmãos Montello e outros tantos. Contribuiu também neste sentido seu casamento, em 1956, com o ilustre físico, professor emérito da UFRJ, José Leite Lopes (1918-2006), com quem teve oportunidade de compartilhar a experiência desse convívio.

Esse espírito de verdadeira Universidade foi avivado por Maria Laura durante seu exílio, no qual manteve contato com outros expoentes da cultura brasileira, também exilados, e do exterior. Esse clima de luta em prol da cultura brasileira, em campos distintos, uniu e criou laços de amizade entre pessoas de áreas as mais diversas, que ela fazia questão de cultivar.

Todos esses fatos, aliados a características de sua personalidade comunicativa, acolhedora e de grande cultura geral, podem ter contribuído para o pensar "grande" que distinguia Maria Laura. Em relação à UFRJ, lutou até a sua morte contra a compartimentalização dessa universidade, muito acentuada com a reforma implementada pelo governo da ditadura militar. Particularmente, não admitia pensar em matemática sem relação com as demais atividades humanas, como, por exemplo, arte e história. Criticava também o afastamento físico entre os institutos básicos, a Faculdade de Educação e o Colégio de Aplicação.

\section{Capacidade de superação}

A capacidade de superação da Maria Laura manifestou-se em diversas ocasiões em que, diante de dificuldades de ordem pessoal e familiar, reuniu forças entre amigos, colegas de trabalho para ultrapassá-las. Mas essa força vinha sobretudo de sua personalidade, ao mesmo tempo muito forte, generosa, leal, dedicada e segura dos seus valores e ideais.

Sofreu a decepção de, como aluna recém admitida, ver a Universidade do Distrito Federal, criada por Anísio Teixeira, ser fechada por motivos políticos. Pas- 
sou então para a Faculdade Nacional de Filosofia da Universidade do Brasil, onde construiu sua bela carreira acadêmica.

Em relação a essa carreira, é conhecida a batalha que empreendeu em 1949, ainda na Faculdade Nacional de Filosofia, para ter reconhecido o seu trabalho de livre docência, que lhe deu o título de doutor em Matemática. O sucesso absoluto nessa batalha contribuiu fortemente para a sua projeção na comunidade acadêmica de Matemática da época, particularmente, naquela Faculdade. Esse trabalho da Maria Laura, intitulado ESPAÇOS PROJETIVOS - RETICULADO DE SEUS SUB-ES$P A C ̧ O S$, orientado pelo matemático português Professor António Aniceto Ribeiro Monteiro (1907-1980), foi publicado na revista Summa Brasiliensis Mathematicae 2 $\mathrm{n}^{\circ} 7$ (1950), pp. 95-112, e muito bem acolhido entre os especialistas internacionais, por conter um teorema definitivo no assunto.

Mais tarde, em 1969, sofreu o seu mais duro golpe de ordem profissional que, mais uma vez superou: a aposentadoria precoce e compulsória e o seu exílio. Ela se referia a esse período de afastamento da UFRJ como seu "cone de sombra".

Ao ser reintegrada à universidade, com a Lei da Anistia, em 1980, Maria Laura tinha um sonho que não se realizou: ter um Departamento de Educação Matemática no Instituto de Matemática da UFRJ. Como era próprio da sua personalidade, aproveitou essa impossibilidade para reunir professores de vários departamentos do Instituto em um trabalho nos moldes em que acreditava.

Muito da energia que trazia àquela ocasião tinha sido gerada à custa da triste experiência no exílio, breve nos EUA, e mais longo em Estrasburgo, na França. Durante os poucos anos em que esteve em Estrasburgo, entrou em contato com $\mathrm{Me}$ Lucianne Felix e Georges Glaeser e logo tornou-se pesquisadora em Educação Matemática do IREM (Institute de Recherche en Enseignement de Mathematiques) da Universidade Louis Pasteur, nessa cidade. A palavra tornar-se expressa a mudança de rumo na carreira de Maria Laura, até então focada na matemática, e interrompida com a sua aposentadoria forçada. Em vez de se abater com a situação, abraçou a nova linha de estudos e pesquisa, como oportunidade de fazer desabrochar seu gosto pelo ensino de matemática e preocupação com a formação de professores.

No entanto, não queria copiar no Brasil a experiência do IREM. Fazia a ela a crítica de que, lá, os professores das escolas recebiam prontas as atividades desenvolvidas na Universidade. Acreditava no entanto que estes deveriam ser atores do processo de seu desenvolvimento. Foi a partir dessa convicção que Maria Laura criou o Projeto Fundão e tornou-se um dos maiores expoentes na área de Educação Matemática do Brasil.

Essas características comprovam o espírito empreendedor da Maria Laura, que a moveu a criar e conduzir o Projeto Fundão. 


\section{O Projeto Fundão}

Em 1983, ao saber do Edital do Subprograma de Educação para a Ciência (SPEC) do PADCT da CAPES, Maria Laura congregou representantes dos Institutos de Matemática, Física, Química, Biologia e Geociências (Departamento de Geografia) para elaborar e submeter uma proposta de um projeto interdisciplinar da UFRJ. Nasceu assim, em 1983, o "Projeto Fundão - Desafio para a Universidade". Ao longo desses 30 anos do Projeto Fundão muita coisa aconteceu, alguns setores perderam o fôlego e, atualmente, há apenas dois setores atuantes: Matemática e Biologia. Maria Laura foi coordenadora geral do Projeto Fundão ao longo desses 30 anos, e coordenadora do setor Matemática nos últimos anos, a partir de 1996.

Seu espírito empreendedor se manifestou novamente quando, para comemorar 10 anos do SPEC, um edital da CAPES convocou todos os projetos filiados a esse subprograma a submeter os materiais produzidos nesse período a uma avaliação. As três produções melhor avaliadas de cada área seriam publicadas sob a forma de livros. Maria Laura, então, animou a equipe do Setor Matemática do Projeto Fundão a agrupar as diversas apostilas já produzidas pelo grupo. Num esforço conjunto devido ao curto espaço de tempo, e estimulados por Maria Laura, foram submetidos três trabalhos: Números: Linguagem Universal (organizado por Jovana Rezende e Vânia Maria Pereira dos Santos), Razões e Proporções (organizado por Lucia Tinoco) e Geometria na Era da Imagem e do Movimento (organizado por Lilian Nasser e Maria Laura Mouzinho Leite Lopes). Esses trabalhos venceram a concorrência dos demais projetos, e receberam financiamento para publicação. Foram os três primeiros livros de uma ampla produção do Setor Matemática do Projeto Fundão, que hoje soma 20 livros.

Devido a seu espírito empreendedor, Maria Laura não se deixava abater por obstáculos que, a princípio, pareciam impedir a realização de ações do grupo. Em 1996, o Projeto Fundão recebeu o convite da Editora do Brasil para escrever uma coleção de livros didáticos para o $1^{\circ}$ segmento do Ensino Fundamental. A grande maioria dos professores do grupo manifestou dificuldade em realizar tal empreitada, devido ao curto espaço de tempo. No entanto, Maria Laura enfrentou esse desafio e passou a reunir, em sua casa, as professoras que se dispuseram a desenvolver o trabalho. Em pouco tempo foi criada uma coleção inovadora de livros, que recebeu, na época, excelente avaliação no Programa Nacional do Livro Didático (PNLD/MEC).

\section{Maria Laura coordenadora de grupo no Projeto Fundão}

Enquanto durou o SPEC, Maria Laura foi coordenadora geral do Projeto Fundão. Como tal, coordenou também a Rede Rio de Janeiro do Subprograma, que contava 
com cinco Projetos de instituições distintas do Estado, inclusive o GEPEM e o Projeto Fundão. Nesse período, foi indicada para integrar o GT que geria o SPEC em nível nacional, com atuação de destaque. Assim, apenas quando este Subprograma foi encerrado Maria Laura pode dedicar-se à coordenação de um dos grupos do Projeto Fundão, o que lhe deu muita satisfação.

Maria Laura gostava de desafios, os temas escolhidos pelos grupos que coordenou no Projeto Fundão eram, ou sobre assuntos não usualmente abordados na educação básica, mas que ela defendia que deveriam ser, ou temas para ela ainda desconhecidos. Elizabeth Ogliari, uma das professoras multiplicadoras de seu grupo reproduz assim uma de suas falas "Meninos, vamos pesquisar alguma coisa que eu ainda não sei". Trazia consigo esta imensa vontade de aprender e procurava transmiti-la aos mais jovens, com os quais mantinha um laço de cumplicidade, estimulando- os a falar, chamando-os ao debate, principalmente se mais tímidos, e por vários momentos pedindo que os professores mais experientes dessem vez a eles na palavra. Valorizava o saber e a experiência de cada integrante de sua equipe, sendo bastante compreensiva com as dificuldades que porventura apresentassem. Sendo portadora de ampla cultura, indicava fontes de pesquisa que enriquecessem a formação acadêmica de seus parceiros. Acima de tudo, sua postura traduzia um compromisso total com a educação.

No Projeto Fundão, o primeiro grupo temático que coordenou foi Formação de Formadores de Professores, realizando pesquisa para o INEP em 1989 e 1990, com o objetivo de detectar deficiências do antigo Curso Normal, que formava professores do primeiro segmento da Educação Fundamental. A seguir estimulou o seu grupo a desenvolver o tema Tratamento da Informação, cujo título por si só confirma a característica inovadora de sua personalidade.

Sobre esse assunto, o grupo coordenado por Maria Laura publicou dois livros: Tratamento da Informação - explorando dados estatísticos e noções de probabilidade a partir das séries iniciais e Tratamento da Informação - atividades para o Ensino Básico. O primeiro desses dois livros, fruto de pesquisa de cerca de dois anos, foi lançado em 1997, quando pouco se mencionava sobre o assunto, que só começou a receber maior atenção após a publicação dos Parâmetros Curriculares Nacionais (BRASIL, 1998). O próximo tema que viria a escolher com seu grupo foi Combinatória e Probabilidade. O produto desse trabalho, que alia ao conteúdo em si histórias relacionando a Matemática com o cotidiano, foi publicado sob o título Histórias para introduzir noções de combinatória e de probabilidades. Maria Laura acreditava que o desenvolvimento conjunto da língua com a matemática era de muita importância para a educação do aluno. A seguir, o grupo escolheu o tema de Grafos, e publicou o livro Grafos: jogos e desafios. Esse assunto ainda hoje não consta dos 
programas do Ensino Fundamental. Com sua habilidade, Maria Laura e seu grupo conseguiram adaptar atividades para esse nível de ensino, envolvendo situações nas quais a teoria de grafos é usada como ferramenta para sua representação e solução. Essas atividades incluíam aspectos históricos e da realidade social contemporânea.

O último trabalho que vinha orientando envolvia História da Geometria em Sala de Aula. Com base nos estudos de geometrias Euclidianas e não Euclidianas, o grupo vinha realizando trabalho relacionando a importância da intuição e da lógica no ensino de matemática, especialmente da geometria. Este trabalho vem sendo concluído pelo grupo, seguindo a meta que Maria Laura havia colocado a princípio.

Muito mais poderíamos dizer sobre a grande educadora, inspiradora e amiga Professora Maria Laura. Ficamos por aqui, com a certeza de que seus ensinamentos, sua firmeza de caráter e de propósitos nos guiará sempre.

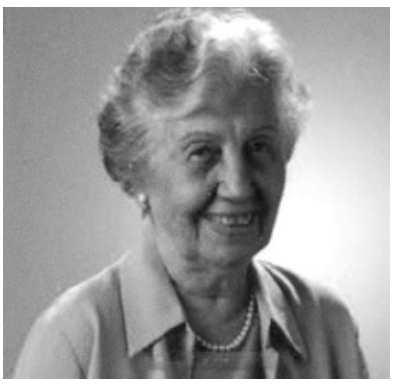

Maria Laura na ocasião da sua Emerência, 1996.

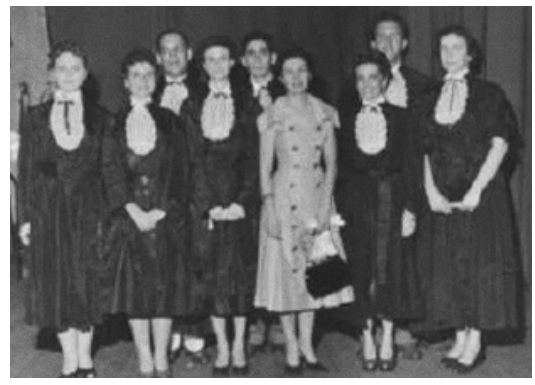

Maria Laura em formatura da FNFi, com Estela K Fainguelernt à direita, 1955.

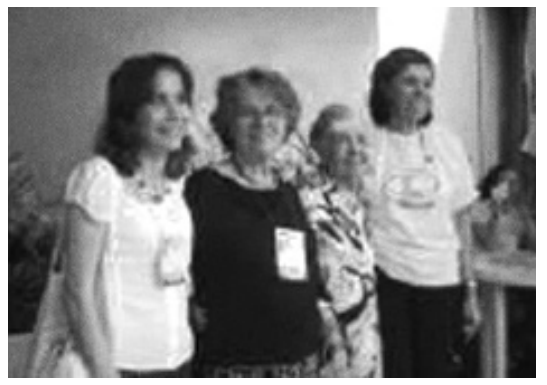

Claudia, Lucia, Maria Laura e Lilian nos 25 anos do Projeto Fundão, 2008. 


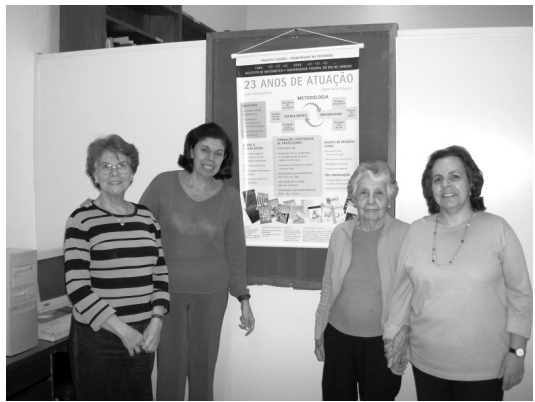

Lucia, Lilian, Maria Laura e Elizabeth Garnier em poster do Projeto Fundão no Congresso de Extensão da UFRJ, 2006.

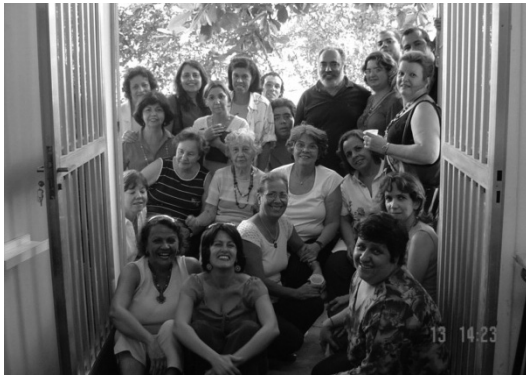

Equipe do Projeto Fundão em confraternização no Natal de 2004.

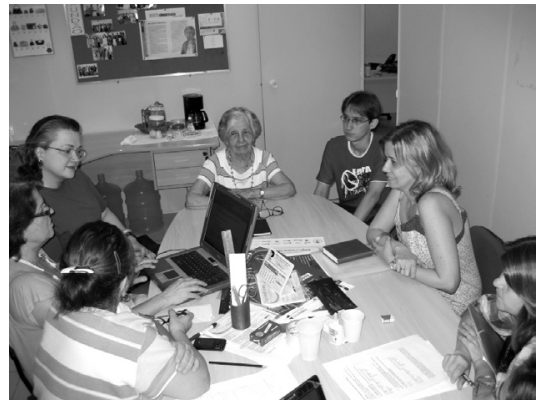

Maria Laura (ao centro) reunida com seu grupo de trabalho, 2010.

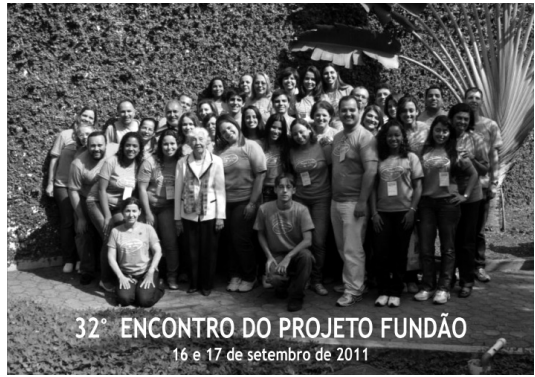

Equipe do Projeto Fundão no 32 o Encontro do Projeto, 2011.

\section{Referências}

BRASIL. SECRETARIA DE EDUCAÇÃO FUNDAMENTAL. Parâmetros Curriculares Nacionais: Matemática. Brasília. MEC/SEF, 1998.

LEAL, M e LOPES, A. L. (Org). Maria Laura: Homenagem da Pró-Reitoria de Extensão - UFRJ. Rio de Janeiro: Pró-Reitoria de Extensão da UFRJ, 2013.

PEREIRA, Pedro Carlos. A Educadora Maria Laura: contribuições para a constituição da Educação Matemática no Brasil. Tese (Doutorado em Educação Matemática) - Centro das Ciências Exatas e Tecnologias, PUC-SP, São Paulo (SP), 2010. 